\title{
Addiction and Violence Prevention in the United States
}

\author{
Christina Pinard* \\ Department of Psychology, The Chicago School of Professional Psychology, USA
}

*Corresponding author: Christina Pinard, Department of Psychology, The Chicago School of Professional Psychology, USA.

Received Date: March 20, 2020

Published Date: April 28, 2020

\section{Guest Editorial}

Violence prevention includes deliberate measures to prevent acts of violence. Data Collection: National Crime Victimization Survey [1] notes that violent crimes include murder, assault, sexual assault, robbery, and rape and the Federal Bureau of Investigation [2] identifies that violent crimes rose from 2013 to 2017, making violence prevention a necessary undertaking. Haskell R, et al. [3] discusses that there is a correlation between substance use, mental health and violence; and, while only some of mental health and substance abusers are violent, there is a link between abuse and trauma in their lives.

Lozano-Verduzco I, et al. [4] conducted a study to better understand the experiences of patients regaining violence prior to their rehabilitation. The results of the study indicated that all participants experienced violence at some point in their lives and the most common types of violence reported were emotional violence, economic, physical, and sexual violence. Women are more susceptible than men to experience violence, which increases with substance use. It is important to note that violence affects all communities, but disproportionately affects the adolescent population and people of color. Violence is not limited to women and children-men too can be victims. The Mayo Clinic Staff [5] discusses that domestic violence, also known as intimate partner violence, is difficult to recognize in men, so knowing the signs of abuse are crucial. There are staggering statistics speaking to the serious of violence in the United States. According to the National Coalition Against Domestic Violence [6], 1 in 5 women and 1 in 71 men in the United States has been raped in their lifetime. Also, 5.1 million men in the United States have been stalked in their lifetime, 1 in 4 men have experienced some form of physical violence by an intimate partner and $90 \%$ of children exposed to domestic violence are eyewitnesses to the brutality [7].
The physical effects of violence can include broken bones, bruises, and internal bleeding. However, while the physical impacts of violence are well known, there are economic and mental effects too. The abused may be forced to give his or her abuser their paycheck. Also, many times, victims must take time off of work to deal with the abuse he or she endured, which may cause a loss of revenue. The mental burden of violence can be draining as well. Depression, anxiety, suicidal thoughts and post-traumatic stress disorder are all effects of violence [5]. The World Health Organization [7] reviewed prevention programs and found that while measures are taken to focus on prevention, measures still fall short in making the necessary impact; notably mentioning that violence can not only be predicted, but prevented too. Sound prevention measures are needed to keep men, women and children safe from violence.

There are ways to advocate for violence prevention. You can help to increase awareness! The very first step is to educate yourself on violence prevention. Next, help community members recognize abusive patterns and breaking the cycle. The cycle includes the abuser threatening violence, physical violence, apologizing and promising to change with the offering of gifts, and ultimately repeating the cycle [5]. Encouraging victims to create a meticulous safety plan can be the difference between life and death. Support victims in getting help from the police, religious organizations and mental health experts. Attending bystander intervention trainings can be immeasurable when faced with a situation. Another way to help is by voting for policies that promote measures to minimize gun related injuries and work with your community to create violence prevention initiatives and supporting law makers that discuss plans to help reduce violence. 


\section{Acknowledgment}

None.

\section{Conflict of interest}

No conflict of interest.

\section{References}

1. (2020) National Crime Victimization Survey (NCVS). Bureau of Justice Statistics.

2. Violent Crime Federal Bureau of Investigation.
3. Haskell R, Graham K, Bernards S, Flynn A, Wells S (2016) Service user and family member perspectives on services for mental health, substance use/addiction, and violence: a qualitative study of their goals, experiences and recommendations. Int J Ment Health Syst 10: 9.

4. Lozano-Verduzco I, Marín-Navarrete R, Romero-Mendoza M, Tena-Suck A (2016) Experiences of power and violence in Mexican men attending mutual-aid residential centers for addiction treatment. Am J Mens Health 10(3): 237-249.

5. Mayo Clinic Staff (2020) Domestic Violence.

6. Statistics (2020) National Coalition Against Domestic Violence.

7. Violence (2017) World Health Organization. 